\title{
Incentives, Equality and Contract Renegotiations: Theory and Evidence in the Chinese Banking Industry*
}

\author{
Hongbin $\mathrm{Cai}^{\dagger} \quad$ Hongbin $\mathrm{Li}^{\ddagger} \quad \mathrm{Li}-\mathrm{An} \mathrm{Zhou}^{\S}$
}

December 2003

${ }^{*}$ We thank Masahiko Aoki, Chong-En Bai, Douglas Bernheim, Loren Brandt, Paul Devereux, Antonio Rangel, Minggao Shen, and especially David de Meza, for very helpful comments. We are indebted to the William Davidson Institute and the Ford Foundation in Beijing for funding the survey work in 1998. All remaining errors are ours.

${ }^{\dagger}$ Department of Economics, UCLA, 405 Hilgard Ave, Los Angeles, CA 90095-1477. Tel: 310-794-6495. Fax: 310-825-9528. E-mail: cai@econ.ucla.edu

${ }^{\ddagger}$ Department of Economics, The Chinese University of Hong Kong. Tel.: 852-2609-8185. Fax: 852-2603-5805. E-mail: lhongbin@cuhk.edu.hk

${ }^{\S}$ Guanghua School of Management, Peking University. Tel: 8610-6275-0431. Fax: 8610-6275-1460. E-mail: zhoula@gsm.pku.edu.cn 


\begin{abstract}
Motivated by observations of the Chinese banking industry, we develop a model of contract renegotiation in which supervisors and managers sign incentive contracts and then renegotiate them after performances are realized. In our model, supervisors have concerns over equality of income distribution of the managers under their supervision, and managers have career concerns which come, within the internal hierarchy of their organizations, largely under their supervisors' discretion. Renegotiations of incentive contracts arise because supervisors try to balance ex post bonus payments to managers with discretionary decisions affecting managers' career prospects or other perks on the job. Even though renegotiation is fully anticipated, incentive contracts affect performance because they define the disagreement payoffs in the renegotiation process and hence affect the parties' final payoffs. We suppose that the bonus benchmark on which supervisors' equality concerns are anchored is endogenously determined. In this setting, we solve the unique equilibrium of the model and derive a rich set of testable hypotheses regarding contract design, performance, and direction and degree of contract renegotiations. We then use a dataset from the Chinese banking industry to test the model's predictions. The empirical evidence quite strongly supports our model. More general implications of our theory are also discussed.
\end{abstract}

Keywords: Incentives; Equality; Contract; Renegotiation

JEL Classification: D80; L14; P31 


\section{Introduction}

Incentive contracts in the real world are often renegotiated, especially within firms and organizations. Renegotiation also plays a very important role in contract theory and has received a great deal of attention. ${ }^{1}$ However, as for contract theory in general, where rapid theoretical advances are contrasted with a long lag of empirical work, to the best of our knowledge, there has not been much empirical study on contract renegotiation. ${ }^{2}$ We are fortunate to have access to a dataset collected from an on-site survey in 1998 that contains valuable information about contract renegotiation in the Chinese banking industry. As with the typical incentive schemes introduced in the course of the reform of China's State Owned Enterprise (SOE) sector since the mid 1980's, managers in local bank branches signed explicit incentive contracts with their supervisors at the beginning of the year that specified bonus payments based on their annual performance. Quite strikingly, those incentive contracts were almost always renegotiated ex post. The dataset contains information about ex ante incentive contracts, realized performance, and ex post contracts, as well as detailed information about branch and manager characteristics, thus opening a rare window into the process of how incentive contracts are designed and then renegotiated.

In trying to connect theory with evidence in the dataset, one finds that the basic assumptions of the standard theories of renegotiation do not fit the reality of the Chinese banking industry. The moral hazard theory of renegotiation does not apply, because here, contract renegotiations

\footnotetext{
${ }^{1}$ In moral hazard models, Fudenberg and Tirole (1990) argue that after the agent exerts effort but before the output is realized, the principal and the agent can achieve mutual gain by renegotiating the incentive contract to fully insure the agent. However, such ex post renegotiation destroys ex ante incentives in the standard optimal contracts. Anticipating the possibility of renegotiation, the principal will design a renegotiation-proof incentive contract that provides weaker incentives than would have existed if renegotiation were not possible. In multi-period adverse selection models, Dewatripont $(1988,1989)$ argues that if the agent's type is revealed in the first period, the principal and the low type agent will want to renegotiate their contract to get rid of any allocation distortions in the optimal static contract. In the same environment, Laffont and Tirole (1988) consider the possibility that once the agent reveals that he is high type in the first period, the principal will want to offer a contract for future periods that takes away the information rent the high type agent enjoys in the optimal static contract. In both cases, ex post renegotiation dampens the truth-telling incentives in the optimal static contract. Taking into account the possibility of ex post renegotiation, the optimal dynamic contracts are usually less efficient than the repeated optimal static contracts.

${ }^{2}$ Prendergast (1999) offers a superb survey of the literature on incentive provision within firms, to which our paper is intended to contribute. See also Gibbons and Waldman (1999) and Chiappori and Salanie (2000).
} 
took place after the realizations of performance, thus could not have been driven by the desire to improve risk-sharing between managers and their supervisors. The adverse selection theory of renegotiation does not apply either, because here, contracts were renegotiated for the current year, not for the future, and thus contracts were not renegotiated with mainly dynamic considerations in mind. Our dataset is drawn from the Chinese banks, but the same phenomena are prevalent also in other SOEs and within governments in China. So the following questions naturally arise. Why were those incentive contracts renegotiated? If it was expected that contracts would be renegotiated, what were the roles of those contracts? What were the effects of ex ante and ex post contracts on performance? ${ }^{3}$

In this paper, we develop a theoretical model of renegotiation to answer these questions, and then use the dataset of the Chinese banking industry to test it. We should stress at the outset that, although our model is motivated by and tested with observations of the Chinese banking industry, the insights yielded by the model can be useful in a much wider range of settings. For ease of exposition, we will present the model and empirical analysis in the China context, and will discuss the general applicability of the model's insights in the conclusion. Specifically, a critical element of our model is that supervisors care about income equality among managers under their supervision. In the setting of the Chinese banking industry, the supervisors' equality concerns may reflect the organizational objectives of the state banks that emphasize income equality. More generally, supervisors may also be motivated to care about equality among their subordinates in order to minimize the influence activities associated with unequal income distributions (Milgrom, 1988). Supervisors' equality concerns can also result from a desire for fairness, inequality aversion or from other social psychological considerations. ${ }^{4}$ Consistent with the assumption that supervisors have equality concerns, it is well documented in the personnel literature that supervisors of firms in developed economies have a tendency to rate all subordinates roughly equally ("centrality bias") and to avoid giving bad ratings for poor performance ("leniency bias"). ${ }^{5}$

\footnotetext{
${ }^{3}$ In line with the so-called renegotiation-proof principle, theoretical analysis of renegotiation typically focuses on optimal contracts that preempt renegotiations (renegotiation-proof). With such contracts, renegotiation does not arise at all in equilibrium. Focusing on renegotiation-proof contracts is extremely convenient for theoretical analysis, but it is not useful for understanding real life renegotiation processes.

${ }^{4} \mathrm{~A}$ large body of literature has emerged recently on fairness and its economic implications. See Fehr and Schmidt (2001) for an excellent survey on experimental and field evidence of fairness and its impact on incentives.

${ }^{5}$ See, for example, Murphy and Cleveland (1991) and Coens and Jenkins (2000). For discussions and references on "leniency bias" and "centrality bias", see Prendergast (1999), section 2.2.
} 
Another critical element in our model is that managers have career concerns on such issues as promotion prospects or perks on their current positions, issues that come largely under the control of their supervisors. The supervisors can help managers to move into better positions (or hinder them from doing so); they can give managers perks or favors and so increase their rents on the job (or they can place obstacles in their way, and so reduce them). Such perks cannot be specified ex ante in incentive contracts, and are at the discretion of the supervisors ex post. We argue that supervisors' equality concerns and managers' career concerns (which are subject to manipulation by the supervisors) create opportunities for mutual gains that constitute the basis for contract renegotiation. In the case of managers with above average performance, their supervisors will want to renegotiate their bonus payments downward in exchange for better promotion prospects or more perks. In the case of those who have below average performance, their supervisors will want to pay them higher bonuses than their ex ante contracts specified but reduce their perks and other favors. Ex ante incentive contracts serve as a disagreement point in the renegotiation process, thus affecting ex post payoffs. Given an ex ante incentive contract, the manager chooses an optimal effort level anticipating how the contract will be renegotiated ex post. The supervisor designs an optimal ex ante incentive contract taking into account the manager's best response and the ex post renegotiation process.

In our model, the supervisor's bonus benchmark, on which her equality concerns are anchored, is endogenously determined. We characterize the equilibrium of the game: the optimal ex ante contracts, the manager's best effort response, performance, and how ex ante contracts will be renegotiated. The model generates a rich set of theoretical predictions about how the endogenous variables_ _ ex ante contracts, performance, ex post contracts, and direction and degree of renegotiation_ _ are affected by exogenous manager and supervisor characteristics and technology conditions. For example, we show that ex ante contracts will have higher power and managerial performance will be better when the supervisor's own incentive intensity is greater, or the manager's career concerns are stronger. Moreover, the greater the supervisor's own incentive intensity or the stronger the manager's career concerns, the more likely ex ante contracts will be renegotiated upwards (higher bonus ex post than specified ex ante) and the greater the degree of renegotiation (i.e., absolute magnitude of renegotiation) will be. While some of our predictions are also consistent with the standard contract theory, the majority of the predictions are specific to our theory of renegotiation, and hence allow sharp empirical testing of our model.

Drawing on the dataset from the Chinese banking industry, we conduct empirical tests of the predictions of the model. The empirical results provide evidence that quite strongly supports 
our theory. In particular, we find that the supervisor's own incentive intensity has positive and statistically significant effects on both the incentive intensity in the ex ante managerial contracts and branch performance. Younger managers who have stronger career concerns tend to have more highly powered contracts, and perform better than their older peers. Moreover, when the supervisor's own incentive intensity is greater or the manager is younger, it is more likely that the bonus payments will be adjusted upwards and the adjustment will be larger. For example, according to our estimation, if a branch manager is 5 years younger than the mean, the chance for an upward renegotiation will be 6-10 percent higher. The evidence here suggests that our model, with endogenously determined bonus benchmarks, fits the data pretty well.

By incorporating some essential organizational features into the standard agency framework, we show that renegotiations of incentive contracts arise in equilibrium as a result of the trade off between supervisors' equality concerns and managers' career concerns. Incentive contracts do affect performance, but they do so through mechanisms which are more complicated than the standard agency model suggests. Recently, a number of papers, e.g., Groves et at (1994), Li (1997) and Jefferson and Rawski (1999) have tried to estimate whether and by how much the incentive schemes in Chinese SOEs affected firm productivity and financial performance. Overall, they found positive correlations between incentive intensity and firm performance. However, in light of our theoretical results and empirical findings, it may be an over-simplification to interpret the positive correlations in the way described in the standard agency model. Given that incentive contracts were typically renegotiated, the incentive schemes introduced in the Chinese SOE reforms helped improve performance, most likely because they constrained the renegotiation outcomes and therefore affected the managers' payoffs. Thus, the correlation between performance and actual bonus payments may in fact underestimate the actual incentives managers could look forward to when deciding how hard to work, because exceptionally good (bad) performance was more likely to be associated with downward (upward) renegotiation of bonus payments.

Our paper contributes not only to the renegotiation literature, but also to the literature on incentives within firms. In particular, the spirit of our paper is closely related to that of Prendergast (2002a). Like Prendergast (2002a), we enrich the standard agency model with important organizational features of firms in order to explain phenomena that are inconsistent with the standard model. In one model Prendergast (2002a) develops to show positive correlation between risk and incentives, a supervisor cares about the wage income of her subordinate either negatively or positively (the degree is her private information), and hence may distort her evaluation of the subordinate's performance. The relationship between supervisors and their subordinates 
envisioned by Prendergast (2002a) is very similar to that in our paper: (i) supervisors are themselves employees of the firm and have their own objectives other than profit maximization; (ii) supervisors care about the wage incomes of their subordinates; (iii) supervisors have control over bonus payments to their subordinates. Because of our different objective, our model differs from Prendergast (2002a) in that: (i) whereas in our model, supervisors care about wage equality among their subordinates, Prendergast (2002a) supposes that supervisors will display favoritism towards individual subordinates; (ii) whereas in our model, supervisors design incentive schemes for their subordinates, in Prendergast (2002a) bonus schemes are decided by firms; and (iii) a feature that is crucial in our model but is absent in Prendergast (2002a) is that supervisors in our model have control over their subordinates' career concerns and rent-on-the job.

The rest of the paper is structured as follows. The next section outlines the institutional backgrounds of incentive contracting and renegotiation in the Chinese banking industry. In Section 3, we build the model and derive its theoretical predictions. In section 4 we describe the data. In Section 5, we present the results of our empirical testing. Section 6 contains concluding remarks.

\section{Institutional Backgrounds in the Chinese Banking Industry}

In this section, we briefly describe the institutional backgrounds of the rural financial institutions in China: the Agricultural Bank of China (ABC) and the Rural Credit Cooperatives (RCCs). The discussion below serves two purposes. First, it familiarizes readers with the institutional context of our dataset, which was collected from an on-site survey of these two financial institutions. Second, it provides motivations and justifications for some key elements of our model.

The ABC is one of the four specialized state-owned banks in China. ${ }^{6}$ The RCCs were formerly under the supervision of $\mathrm{ABC}$, but together they attained the status of an independent financial institution in 1994. The ABC serves clients both in urban and rural areas, with headquarters in Beijing and branch offices at locations at every administrative level. ${ }^{7}$ The RCCs only provide financial services to rural areas, with headquarters at the county level, which collectively make up the Federation of RCCs (xin yong lian she). In general, both the ABC and the RCCs establish

\footnotetext{
${ }^{6}$ The other three are the Industrial and Commercial Bank of China, the Construction Bank of China, and the Bank of China.

${ }^{7}$ The administrative levels in China are, from highest to lowest, central, provincial, prefecture, county and township.
} 
branches in each township, paralleling the territorial structure of the government system in order to minimize overlapping within the same institution. These two institutions are very much alike in terms of internal management and operation, except perhaps that the RCCs' collective ownership status may allow them somewhat more flexibility in complying with central policies. The ABC and RCCs currently dominate the formal financial system in rural China. As of the late 1990s, they accounted for nearly 80 percent of total rural deposits and loans (Park et al., 1997).

In the pre-reform era, Chinese state-owned banks, like other SOEs, were subject to rigid central planning and control. No monetary incentives were given to managers and workers; their wages were fixed by the central planning agency in accordance with pre-determined formula linking wages to worker characteristics such as age, seniority, and position, but not to performance. Once employed, workers were guaranteed life-time employment. Since the early 1980s, as part of the enterprise reform programs, China has sought to reform its banking sector. As is characteristic of the Chinese approach to the reform of the SOEs, China has avoided the privatization of large SOEs and state banks, but has focused instead on improving their internal management and efficiency. As a major reform initiative to improve the performance of state-owned banks, in particular to increase deposits and reduce non-performing loans, the government introduced a bonus system into the sector in the mid 1980s (Dipchand et al, 1994). Typically, supervisors sign a so-called responsibility contract with each individual branch manager. The contract, normally signed on an annual basis, specifies a formula tying the branch manager's monetary rewards to branch performance. For both the ABC and the RCCs, county-level bank supervisors determine incentive contracts for township branch managers. While the details of the incentive system (such as the kinds of contracts and the autonomy allowed to supervisors by the central government) have been evolving over the years of the reform, its basic structure has remained more or less the same. Moreover, while the economy has been growing rapidly with market forces playing an increasingly important role, the internal organization structure of the large SOEs and state banks has remained quite stable. In particular, in the late 1990's, there was still no active outside managerial market, hence managers' careers were largely confined within the enterprise or bank that first employed them. It remains difficult to dismiss or lay off managers and workers. ${ }^{8}$

\footnotetext{
${ }^{8}$ Besides introducing incentive schemes, the Chinese government's efforts to reform the SOEs and state banks have focused on such aspects as reducing administrative intervention, granting more autonomy, and putting more emphasis on commercial objects. For an excellent description and discussion of the SOEs and SOE reforms, see Naughton (1995).
} 
In order to assess how and how well the incentive system introduced in the Chinese SOE reforms performs, it is important to understand how the incentive schemes operate to impact performance in the institutional environment of the Chinese SOEs and state banks. One puzzling phenomenon is that actual bonus payments to managers at the end of the year systematically differ from those agreed upon at the beginning of the year. In our dataset, contract renegotiation occurred in more than 90 percent of cases. Such contract renegotiation is common in other SOEs. Typically, good-performing SOE managers get downward revisions of promised bonuses, while bad-performing ones are not "punished" financially, as they are supposed to according to their original contracts (see, e.g., Shirk, 1993). Similar renegotiation phenomena are also frequently observed in the enforcement of intergovernmental fiscal agreements between the central government and local governments. For example, the central government "created" numerous means to level up revenue-submission ratios for those provinces of good fiscal performance, including "forced borrowing" or reclaiming central ownership of lucrative local firms (Wong et al., 1995; Ma, 1997).

This kind of renegotiation of incentive contracts is puzzling, because it does not fit in with the standard explanations. One obvious candidate for an explanation would be that incentive contracts are not carried out as they were agreed upon because they cannot be enforced by the shaky Chinese court system. But this cannot answer the question, why are those contracts written at all, if they are expected to be non-binding ex post? And why do they seem to have significant impacts on performance, according to various empirical studies (e.g., Groves et al., 1994; Li, 1997; and Jefferson and Rawski, 1999)? The standard theories of renegotiation based on adverse selection and moral hazard cannot explain contract renegotiations in the Chinese banks and SOEs. Renegotiations of incentive contracts in the Chinese banks and SOEs take place after performance is realized. This is inconsistent with renegotiation in moral hazard models (e.g., Fudenberg and Tirole, 1990), where renegotiation can only happen after the agent exerts effort but before the output is realized. It is also different from renegotiation in multi-period adverse selection models (Dewatripont, 1988 and 1989; Laffont and Tirole, 1988) in that contracts can be renegotiated from the current period to future periods, but the contracts of the current period are binding. Moreover, the fact that the vast majority of contracts are renegotiated in our dataset is in sharp contrast with the renegotiation-proof principle in the theoretical literature.

To understand incentive contracting and renegotiations in the Chinese banks and SOEs, we need to incorporate important features of the institutional environment into the standard agency model. In particular, the following features are critical. First, managers in the state banks and 
SOEs have strong career concerns within their enterprises because outside options are very limited due to the lack of active managerial markets. Career concerns include promotion prospects in the hierarchy of the enterprise, as well as managers' general well-being on the job, embracing such things as perks and autonomy. Note that here we use the term, career concerns, to cover all the things that affect rents on the job managers get in the state enterprises and banks. This marks something of a difference in emphasis from the existing literature (e.g., Holmstrom 1999, Gibbons and Murphy 1992), which stresses the role of an effective managerial market and the incentive effects of market perception on managers. The career concerns that originate in the internal labor market exist side by side with those that arise from external labor markets. As the managerial market develops in China, we expect it to play an increasing role in shaping the enterprise-supervisor-manager relationships within the state banks and SOEs. But career concerns in the internal labor market will remain important.

Second, as is typical in the strictly hierarchical Chinese banks and SOEs, supervisors have a great deal of discretion over the careers of managers under their supervision. Supervisors control evaluation, recommendation, and other decisions contributing positively or negatively to managers' promotion prospects. Supervisors typically also have discretion over managerial perks (e.g., company apartments, cars, etc) and whether and how far to intervene in the management of local branches (e.g., on personnel decisions, task assignments) and so to affect managers' rents on the job. A supervisor's discretion over managers' career issues can come in a variety of forms, many of which are very hard to specify in advance and extremely difficult for outsiders to verify (e.g., membership of a delegation to visit the United States on a "business trip"). As a result, it is impossible for a supervisor and each manager under her supervision to reach an agreement on all future decisions regarding the manager's career concerns that she will make.

Third, supervisors themselves are employees in state banks and SOEs which are burdened with a rigid institutional system, and whose objective functions are quite different from that of the principal in the standard agency model. Specifically, they themselves come within the same incentive system as the managers under their supervision, and hence care about the overall performance of branches they are responsible for. But they are not mere profit or output maximizers. As employees of the state banks and SOEs, supervisors have to take into account the goals and objectives of their organizations. The SOEs and state banks have a quite strong tendency towards income equalization among subdivisions or subordinates, which is closely related to the "paternalism" referred to by Kornai $(1980,1992)$ when he describes the typical social relation between superiors and subordinates in SOEs. More generally, supervisors in large 
organizations may care about income equality among their subordinates because they want to minimize costly influence activities arising from unequal distribution of wages and bonuses (Milgrom, 1988). Moreover, supervisors in the Chinese state banks and SOEs probably have stronger tendencies toward "centrality bias" and "leniency bias" than their counterparts in firms in the developed economies. Combining these reasons, supervisors in the Chinese banks and SOEs can have a quite strong concern for equality, to maintain balance among their managers in terms of wages and bonuses. ${ }^{9}$

In the next section, we build a simple model to capture these important features of incentive contracting and renegotiations in the Chinese state banks and SOEs, and show that they give rise to a renegotiation process different from what is described in the standard models of renegotiation.

\section{$3 \quad$ The Model and Theoretical Analysis}

In our model, a supervisor S (county branch manager) supervises a number of ex ante identical managers (township branch managers). Let $\mathrm{M}$ be a representative manager. To provide a benchmark, consider the "old system" before the state bank introduced incentive schemes. In the old system, each year $M$ is expected to exert some minimally acceptable effort. In practice it is very difficult to fire $\mathrm{M}$ except in very unusual situations (e.g., criminal acts). As long as $\mathrm{M}$ "does his job," he is paid a fixed wage $w_{0}$. The wage $w_{0}$ is fixed in two senses. First, it is independent of the manager's performance. It usually depends on the manager's years of service, position, degree and perhaps other personal or geographic adjustments. Second, the wage formula is fixed by the bank headquarters in Beijing, so it is out of the control of S. The supervisor herself is in a similar environment, except that she is one level above $M$ in the bank's hierarchical structure. While not being able to alter M's employment status or his wage, the supervisor does have some discretion over M's conditions of employment. One of the discretions

\footnotetext{
${ }^{9}$ Supervisors may be also concerned about equality of career prospects or other on-the-job rents among their subordinates, but probably to a much lesser degree than equality concerns over income distribution of their subordinates. Promotions are intrinsically unequal, so supervisors are not expected (and will not be able) to act "equally" with regard to promotion prospects among managers under their supervision. In addition, while managers' incomes can always be compared on a dollar to dollar basis, it can be very difficult to compare perks and favors and other types of on-the-job rents as between different managers. A related problem is that it can be very hard to discern whether supervisors' discretionary decisions over managers' career issues are purely favors (which would require justification from the equality perspective) or purely business decisions. For these reasons, we suppose that supervisors' equality concerns are over income distribution of managers.
} 
$\mathrm{S}$ has over M is on M's career prospect in the bank, in the form of evaluation, recommendation, and other decisions contributing positively or negatively to M's promotion prospects. S also has discretion over whether and how much to intervene in M's management of his branch (e.g., on personnel decisions and task assignments), which also affects M's well-being.

To model the supervisor's discretion in the simplest way, suppose $\mathrm{S}$ makes a decision $d \in[0, D]$, where $d$ is interpreted as perks or favors S gives M. In this case, M's payoff is $u=w_{0}+\beta d$, where $\beta \in[0, D]$ is a parameter measuring how important M's career concerns are. Here M's effort cost is normalized to zero for the minimal acceptable effort. S's payoff in the old system is $v=A-0.5 d^{2}$, where $A$ is a positive constant depending on her own fixed wage (and perhaps perks and favors she gets from her superior), and $0.5 d^{2}$ is the cost to $\mathrm{S}$ of giving $d$ to M. For ease of exposition, we will sometimes call $d$ the "perks" $\mathrm{S}$ gives $\mathrm{M}$.

Clearly, in the old system, $\mathrm{S}$ will choose $d=0$ and will get a payoff $v=A$; and $\mathrm{M}$ will exert the minimal acceptable effort and get a payoff of $u=w_{0}$.

Now suppose a new incentive scheme is introduced to motivate the manager to exert effort beyond the minimal acceptable level. Suppose M can exert extra effort $e$ to improve the performance of his branch: $x=e+\theta$, where $\theta$ is a random variable. ${ }^{10}$ For simplicity, and to ensure non-negative $x$, we assume $\theta$ is uniformly distributed on $[0, Z]$. We will call M's extra effort beyond the minimal acceptable level simply his "effort". M's private effort cost is $0.5 \gamma e^{2}$, where $\gamma>0$ is a cost parameter. To motivate $\mathrm{M}$ to exert effort, $\mathrm{S}$ offers $\mathrm{M}$ a linear incentive contract: $w=w_{0}+\alpha x$, where $\alpha \geq 0$ measures the incentive intensity of the contract. We suppose that $\mathrm{M}$ is risk neutral, thus his payoff function is $u=w_{0}+\beta d+\alpha x-0.5 \gamma e^{2}{ }^{11}$

In the new incentive system, S's payoff is $v=A-0.5 d^{2}+(r-\alpha) x-0.5 \lambda(\alpha x-\bar{b})^{2}$. The first two terms $A-0.5 d^{2}$ are just as before. The third term $(r-\alpha) x$ reflects the fact that $\mathrm{S}$ benefits from good performance by $\mathrm{M}$ (where parameter $r>0$ measures how much $\mathrm{S}$ values M's performance) and a bonus payment to $\mathrm{M}$ reduces her payoff. The reason for this is that in

\footnotetext{
${ }^{10}$ For simplicity, we consider one-dimensional effort that can be a composite index of multidimensional efforts. See Footnote 19 for further discussion on this.

${ }^{11}$ This implies that, compared with the old system, $\mathrm{M}$ gets an increase of $0.5 \alpha Z$ in expected wage without having to exert any extra effort. This is in fact consistent with the reality in China, where some rents in the form of guaranteed bonuses are used to induce state employees to participate in the incentive schemes. In the point system observed in our dataset, substantial weights were assigned to performance measures, such as bank safety, that could almost guarantee high points. Theoretically, the model is not affected if the fixed wage portion is reduced by the expected rents managers get from participating in the incentive system.
} 
the new incentive system $\mathrm{S}$ is evaluated and rewarded by her superior based on the aggregate performance of all branches under her supervision. The last term $-0.5 \lambda(\alpha x-\bar{b})^{2}$ represents S's equality concerns. Under the new incentive system, managers in different township branches will get different bonuses based on their performance. The variable $\bar{b}$ denotes the "bonus benchmark" which the supervisor uses to compare M's bonus payment, and the parameter $\lambda$ measures how strongly $\mathrm{S}$ cares about wage equality. How $\bar{b}$ is determined will be specified later. Roughly speaking, $\bar{b}$ can be thought of as the average bonus paid to all managers, hence $\alpha x-\bar{b}$ measures how far a particular M's bonus is from the average.

We study the following game. At the beginning of the year, $\mathrm{S}$ chooses an ex ante incentive contract, that is, incentive intensity $\alpha$. After signing the incentive contract with $\mathrm{S}, \mathrm{M}$ chooses an effort level $e$. The performance measure $x$ is then observed by both $\mathrm{M}$ and $\mathrm{S}$ near the end of the year. At the end of the year, $\mathrm{S}$ will choose the amount of perks or favors, $d$, that she will give to M. Immediately before that, $\mathrm{M}$ and $\mathrm{S}$ can negotiate about $d$ and renegotiate $\alpha$. Let us call the renegotiated incentive scheme $\alpha^{\prime}$. We suppose that $\mathrm{S}$ has all the bargaining power in the renegotiation process. This is for simplicity and fits well the reality of the Chinese state bank. We assume that $\mathrm{S}$ cannot commit to a specific $d$ at the beginning of the year. This is reasonable, because $\mathrm{S}$ has a wide range of discretions over M's career concerns and well-being on the job, so that it is very difficult to even specify all of them ex ante. Furthermore, in China's institutional environment, $\mathrm{S}$ is not contractually bound to keep her promise to choose a particular $d$.

We solve the subgame perfect equilibrium (henceforth "equilibrium") of the game.

\subsection{Renegotiation Stage: Ex Post Incentives}

In the renegotiation stage, given the ex ante incentive scheme $\alpha$ and the realized performance measure $x, \mathrm{~S}$ chooses $d$ and a new bonus scheme $\alpha^{\prime}$ to

$$
\max _{d, \alpha^{\prime}} \quad v=A-0.5 d^{2}+\left(r-\alpha^{\prime}\right) x-0.5 \lambda\left(\alpha^{\prime} x-\bar{b}\right)^{2}
$$

subject to M's participation constraint:

$$
w_{0}+\beta d+\alpha^{\prime} x-0.5 \gamma e^{2} \geq w_{0}+\alpha x-0.5 \gamma e^{2}
$$

which can be simplified as $\alpha^{\prime} x+\beta d \geq \alpha x$.

If M's participation constraint is binding, then substituting $\alpha^{\prime} x=\alpha x-\beta d$ into the objective function (and ignoring constant terms) gives $-0.5 d^{2}+\beta d-0.5 \lambda(\alpha x-\beta d-\bar{b})^{2}$. Solving for the first order condition, we get 


$$
d^{*}=\frac{\lambda \beta[1 / \lambda-\bar{b}+\alpha x]}{1+\lambda \beta^{2}}=\frac{\lambda \beta[\alpha x-B]}{1+\lambda \beta^{2}}
$$

where we define $B=\bar{b}-1 / \lambda$. We will assume that $\lambda$ is sufficiently large so that $B>0 .{ }^{12} d^{*} \geq 0$, and this requires that $\alpha x \geq B=\bar{b}-1 / \lambda$. Otherwise, $d^{*}=0$. The second order condition is clearly satisfied.

Then the optimal ex post bonus scheme is

$$
\alpha^{\prime}=\alpha-\beta d^{*} / x=\alpha \frac{1}{1+\lambda \beta^{2}}+\frac{B}{x} \frac{\lambda \beta^{2}}{1+\lambda \beta^{2}}
$$

In this case, it can be calculated that S's payoff is $v=A+v_{2}$, where

$$
v_{2}=r x-B-\frac{0.5}{\lambda}-\frac{0.5 \lambda(\alpha x-B)^{2}}{1+\lambda \beta^{2}}
$$

If M's participation constraint is not binding, then $\mathrm{S}$ will set $d=0$. Solving for $\alpha^{\prime}$ from the first order condition, we get

$$
\alpha^{\prime}=\frac{\bar{b}-1 / \lambda}{x}=\frac{B}{x}
$$

The second order condition is clearly satisfied. In this case, it is easy to show that S's payoff is $v=A+v_{1}$, where

$$
v_{1}=r x-B-0.5 / \lambda
$$

Summarizing, we have

Lemma 1 When $\alpha x \geq B$, S will lower $\alpha$ to $\alpha^{\prime}$ in accordance with Equation 2, and in exchange offers $M$ perks $d^{*}$ in accordance with Equation 1. When $\alpha x<B, S$ will increase $\alpha$ to $\alpha^{\prime}=B / x$, and gives $M$ no perks.

Lemma 1 is easy to understand. The variable $B=\bar{b}-1 / \lambda$ can be thought of as an adjusted bonus benchmark. When the bonus payment to $\mathrm{M}$ in accordance with the ex ante contract is larger than the benchmark $B, \mathrm{~S}$ would like to renegotiate it down in exchange for more perks

\footnotetext{
${ }^{12}$ Strictly speaking this is not a proper assumption, since $\bar{b}$ will be endogenously determined. However, as will become clear later, $B \leq 0$ can be easily ruled out in the optimal solution of the model as long as $\lambda$ is sufficiently large. The reason is that for large $\lambda$, the chosen $\alpha$ must be very small for $B \leq 0$. But this cannot be optimal if managerial effort is important.
} 
to M. By Equation (1), the more M's performance exceeds the benchmark (i.e., the greater $\alpha x-B)$, the more perks $M$ will get. By Equation 2, the ex post bonus payment $\alpha^{\prime} x$ is a linear combination of the ex ante bonus payment $\alpha x$ and the benchmark $B$. Consequently, the ex post incentive intensity $\alpha^{\prime}$ is increasing in the ex ante incentive intensity $\alpha$ and decreasing in the realized performance measure $x$. On the other hand, when the bonus payment to M according to the ex ante contract is smaller than the benchmark $B, \mathrm{~S}$ does not need to provide $\mathrm{M}$ with any perk $(d=0)$. But S's equality concern leads her to offer a higher bonus to M.

\subsection{Managerial Optimal Effort Choice}

Given an ex ante incentive intensity $\alpha$, if $\mathrm{M}$ exerts effort $e$, his expected payoff can be calculated as follows. If $\alpha x=\alpha(e+\theta) \geq B$, or if $\theta \geq \bar{\theta}(e)=B / \alpha-e$, then by Proposition 1, M's payoff is $w_{0}+\alpha x-0.5 \gamma e^{2}$ since the participation constraint is binding. If $\theta<\bar{\theta}(e)=B / \alpha-e$, M's payoff is $w_{0}+\alpha^{\prime} x-0.5 \gamma e^{2}=w_{0}+B-0.5 \gamma e^{2}$. Therefore, M's expected payoff is

$$
\begin{aligned}
E u & =w_{0}-0.5 \gamma e^{2}+B \frac{\bar{\theta}}{Z}+\int_{\bar{\theta}}^{Z} \frac{\alpha(e+y)}{Z} d y \\
& =w_{0}-0.5 \gamma e^{2}+B \frac{\bar{\theta}}{Z}+\frac{\alpha}{Z}\left[e Z-e \bar{\theta}+0.5 Z^{2}-0.5 \bar{\theta}^{2}\right]
\end{aligned}
$$

Using $d \bar{\theta} / d e=-1$, solving from the FOC for M's optimal effort gives

$$
e^{*}=\frac{Z \alpha-B}{Z \gamma-\alpha}
$$

For the second order condition to hold, it must be that $\alpha<Z \gamma$. For $e$ to be non-negative, it must be that $\alpha \geq B / Z$. Otherwise, if $\alpha<B / Z$, then $e=0$. Thus, when Equation 7 gives M's optimal effort, it must be that $Z^{2} \gamma>\alpha Z \geq B$. It follows that

$$
\frac{d e^{*}}{d \alpha}=\frac{Z^{2} \gamma-B}{(Z \gamma-\alpha)^{2}}>0
$$

Lemma 2 If the ex ante incentive intensity $\alpha \geq B / Z$, then $M$ will choose effort in accordance with Equation 7; if $\alpha<B / Z, M$ will choose $e=0$. M's optimal effort is increasing in $\alpha$.

Lemma 2 shows that the ex ante contract can provide incentives for managerial effort even if it is anticipated that it will be renegotiated. The reason is that the bonus and perks $\mathrm{M}$ will receive ex post is determined by his ex ante contract when $\theta \geq \bar{\theta}$, thus, greater ex ante incentive 
intensity induces greater managerial effort. Moreover, higher managerial effort reduces $\bar{\theta}$ and hence increases the likelihood that $\mathrm{M}$ gets a higher payoff, which provides an additional incentive for $\mathrm{M}$ to exert more effort.

\subsection{Optimal Ex Ante Incentive Intensity}

Ex ante, $\mathrm{S}$ is to choose an incentive intensity $\alpha$ to maximize her expected payoff in the whole game. Once $\alpha$ is chosen, $\mathrm{S}$ can correctly anticipate M's optimal effort choice given by Lemma 2 . Since managers are ex ante identical, $\mathrm{S}$ will choose the same $\alpha$ for all managers; and managers will choose the same effort level under the same contract (at least in the symmetric equilibrium). Consequently, once $\mathrm{S}$ chooses an incentive contract $\alpha$ for each manager, the expected average bonus payment is determined by $E(\alpha x)=\alpha E x=\alpha\left(e^{*}(\alpha)+0.5 Z\right)$, where $e^{*}(\alpha)$ is M's optimal effort under contract $\alpha$. We suppose that $\mathrm{S}$ uses the expected average bonus as the benchmark bonus, i.e., $\bar{b}=\alpha\left(e^{*}(\alpha)+0.5 Z\right)$. When the number of managers under S's supervision is relatively large, with high probability the realized average bonus will be close to the expected average bonus. ${ }^{13}$ Using the realized average bonus as the benchmark bonus makes the analysis of the model technically much more involved without yielding any additional insights.

By Lemma 2, we need to consider two cases: $\alpha Z \geq B$ and $\alpha Z<B$. However, the latter case can be easily ruled out. In that case, $\alpha Z<B=\bar{b}-1 / \lambda=\alpha\left(e^{*}(\alpha)+0.5 Z\right)-1 / \lambda$, or, $\lambda \alpha\left(e^{*}-0.5 Z\right)>1$. But by Lemma $2, e^{*}=0$, which is impossible. Thus, only the first case $\alpha Z \geq B$ is feasible.

When $\alpha Z \geq B, e^{*}$ is given by Equation 7 , which can be rewritten as $e^{*} Z \gamma-e^{*} \alpha=Z \alpha-B=$ $Z \alpha-\alpha\left(e^{*}+0.5 Z\right)+1 / \lambda$. Hence, we have

$$
e^{*}=0.5 \alpha / \gamma+1 /(Z \gamma \lambda)
$$

Equation 9 gives M's optimal effort response to ex ante incentive intensity, taking into account that the bonus benchmark is determined endogenously. ${ }^{14}$

\footnotetext{
${ }^{13}$ In our data, there are about 20 township branches in each county.

${ }^{14}$ Note that $\alpha Z \geq B$ means $\lambda \alpha\left(e^{*}-0.5 Z\right) \leq 1$. The solution also requires that $B=\alpha\left(e^{*}+0.5 Z\right)-1 / \lambda \geq 0$. Using Equation 9, these conditions require that

$$
\alpha^{2}+\alpha\left(\frac{2}{Z \lambda}-Z \gamma\right) \leq \frac{2 \gamma}{\lambda} \leq \alpha^{2}+\alpha\left(\frac{2}{Z \lambda}+Z \gamma\right)
$$

The first inequality follows from $\alpha<Z \gamma$, the second order condition for the managerial optimal effort; the second inequality is easily satisfied when $\lambda$ is large.
} 
Since $\bar{\theta}=B / \alpha-e^{*}=0.5 Z-1 /(\alpha \lambda)$, S's expected payoff can be written as

$$
E v=A+\int_{0}^{\bar{\theta}} v_{1} / Z d \theta+\int_{\bar{\theta}}^{Z} v_{2} / Z d \theta
$$

where $v_{1}$ and $v_{2}$ are given by Equations 5 and 3, respectively. Solving the optimal $\alpha$ that maximizes $E v$, we have the following result (see the appendix for the proof).

Proposition 1 Suppose $\lambda$ is sufficiently large. The optimal ex ante incentive intensity $\alpha^{*}$ is (approximately) given by

$$
\alpha^{*} \cong \frac{r-\frac{2}{\lambda Z}-\gamma Z\left(1+\frac{1}{4\left(1+\lambda \beta^{2}\right)}\right)}{2+\frac{\lambda \gamma Z^{2}}{12\left(1+\lambda \beta^{2}\right)}}
$$

The optimal managerial effort level $e^{*}$ is $0.5 \alpha^{*} / \gamma+1 /(Z \gamma \lambda)$. M's performance is $x=e^{*}+\theta=$ $0.5 \alpha^{*} / \gamma+1 /(Z \gamma \lambda)+\theta$.

When performance is good, i.e., $\alpha^{*} x \geq B$, or $\theta \geq \bar{\theta}=0.5 Z-1 /\left(\alpha^{*} \lambda\right)$, the ex post incentive intensity $\alpha^{\prime}$ is given by

$$
\alpha^{\prime}=\alpha^{*}\left[1-\frac{\theta-0.5 Z+1 /\left(\alpha^{*} \lambda\right)}{x} \frac{\lambda \beta^{2}}{1+\lambda \beta^{2}}\right]
$$

and when performance is bad, i.e., $\theta \geq \bar{\theta}=0.5 Z-1 /\left(\alpha^{*} \lambda\right), \alpha^{\prime}$ is

$$
\alpha^{\prime}=\alpha^{*}\left[1+\frac{0.5 Z-1 /\left(\alpha^{*} \lambda\right)-\theta}{x}\right]
$$

Proposition 1 characterizes the equilibrium of the whole game. The optimal ex ante incentive intensity $\alpha^{*}$ trades off several effects. Higher incentive intensity motivates $\mathrm{M}$ to exert more effort (Equation 9), resulting in greater expected performance, which increases gross benefit to S, but also increases the total bonus payment to M. In addition to these conventional effects, higher incentive intensity also raises the bonus benchmark that $\mathrm{S}$ uses as the equality measure, thus making it more likely that M's performance falls below the benchmark, and he needs to be paid a higher bonus (and no perks). The expression, $\alpha^{*}$ in Equation 10 reflects these effects and their interactions. Given $\alpha^{*}$, M's optimal effort is given by Equation 9, which is linearly increasing in $\alpha^{*}$. M's effort choice reflects the fact that once his performance is realized, after renegotiation his expected payoff sometimes depends on the ex ante incentive intensity, but at other times is independent of the ex ante incentive contract. Moreover, since higher effort increases the likelihood of the former, this provides additional incentives for M to exert effort. Finally, after 
M's performance is realized, the ex post renegotiation will reduce his bonus payment in exchange for more perks if his performance is above the bonus benchmark, and if not, it will increase his bonus payment (but with no perks).

In deriving the results in Proposition 1, since the exact solution is not easy to obtain, for simplicity we used an approximation by assuming that $\lambda^{2}$ is sufficiently large relative to other parameters of the model (see the proof in the appendix for details). This approximation does not affect the qualitative properties of the solution (except as regards understating the optimal ex ante incentive intensity) and has no effect on the comparative statics results we derive below. The institutional environment in the Chinese state banks also fits well with the assumption of large $\lambda$, where supervisors are "paternalistic" towards their subordinates (Kornai, 1980, 1992).

\subsection{Theoretical Predictions of the Model}

To derive testable hypotheses from the model, we derive comparative statics results of the endogenous variables that are observable in our dataset: ex ante incentive intensity $\alpha^{*}$, performance, and renegotiation, with respect to the model's parameters.

Proposition 2 The optimal ex ante incentive intensity $\alpha^{*}$ is increasing in $r$ and $\beta$, and decreasing in $\gamma$ and $Z$.

Proof: The comparative statics results with respect to $r, \beta$ and $\gamma$ are apparent from inspection of Equation 10. For $Z$, since $\lambda$ is assumed to be relatively large, the term $2 /(Z \lambda)$ in the denominator of Equation 10 will be relatively small. Hence $\alpha^{*}$ should be decreasing in $Z$ Q.E.D.

Thus, the optimal ex ante incentive intensity for the manager is increasing in the supervisor's own incentive intensity $(r)$ and the manager's career concerns $(\beta)$, and decreasing in the effort cost parameter $\gamma$ and the riskiness of the environment $Z$. While the effects of $r$ and $\gamma$ can also appear from the standard principal-agent models, the effects of $\beta$ and $Z$ arise because of the new features of renegotiation in our model.

Since $e^{*}=0.5 \alpha^{*} / \gamma+1 /(Z \gamma \lambda)$ and $x=e^{*}+\theta$, we immediately have

Proposition 3 Managerial performance $x$ is increasing in $r$ and $\beta$, and decreasing in $\gamma$ and $Z$.

Again, the effects of $\beta$ and $Z$ on performance arise because of the new features of renegotiation in our model. The intuition is as follows. When the manager has greater career concerns (greater $\beta$ ), the supervisor can use perks and favors more effectively to reduce his ex post bonus payments 
if he gets above average performance. Since expected ex post bonus payments will be lower, and hence the cost of providing incentives is lower, the supervisor can use higher $\alpha^{*}$ to motivate the manager to work harder. ${ }^{15}$ When the environment is more risky (greater $Z$ ), the manager exerts less effort for a given incentive intensity $\alpha$, because it is more likely that his performance falls below the bonus benchmark, and hence he gets paid the benchmark bonus independent of his effort (Equation 9). This increases the cost of providing incentives, reducing the optimal incentive intensity and performance. ${ }^{16}$

Next, we derive implications on contract renegotiation. Let $\Delta \alpha=\alpha^{\prime}-\alpha^{*}$ be the difference between ex post and ex ante incentive intensity. Then $\Delta \alpha \leq 0$ if $\theta \geq \bar{\theta}=0.5 Z-1 /\left(\alpha^{*} \lambda\right)$. Hence the probability of downward renegotiation (i.e., $\Delta \alpha \leq 0)$ is $1-\bar{\theta} / Z=0.5+1 /\left(Z \alpha^{*} \lambda\right)$. Immediately we have ${ }^{17}$

Proposition 4 The likelihood of downward (upward, respectively) renegotiation is decreasing (increasing, respectively) in $r$ and $\beta$, and increasing in $\gamma$.

Proposition 4 says that the manager's bonus payment is more likely to be renegotiated down ex post relative to the ex ante contract when the supervisor's own incentives are weaker (lower $r$ ), or when the manager has smaller career concerns (smaller $\beta$ ), or when the manager is less responsive to incentives (larger $\gamma$ ). These results follow from the benchmark effect: if the supervisor gives high powered incentives to all the managers under her supervision, the average performance and hence bonus payment will be greater. Since greater ex ante incentive intensity increases the benchmark $B=\bar{b}-1 / \lambda$ (though $\bar{b}$ ) disproportionally more than it increases the expected performance, it is less likely that a manager's performance exceeds the benchmark. Thus, with a higher $\alpha^{*}$, the contract is more likely to be renegotiated upwards. If the bonus

\footnotetext{
${ }^{15}$ Note that in our model, career concerns affect managerial incentives and performance differently than in the existing literature on career concerns, where career concerns are managers' reputations in the labor market. In the context of our model, there is not an active labor market for managers and managers' career concerns are their promotion prospects within the firm.

${ }^{16}$ Note that in the standard principal agent models more risky environments make risk sharing more important for a risk averse agent, and hence incentives will be weaker. This is not the case in our model, since the manager is risk neutral. Rather, more risky environments weaken incentives because ex post renegotiation outcomes will more likely be insensitive to performance.

${ }^{17}$ Since it is uncertain whether $Z \alpha^{*}$ is increasing in $Z$, the comparative statics of $p$ with respect to $Z$ is undetermined.
} 
benchmark is not endogenously determined, but exogenously fixed, then the likelihood of downward renegotiation will be increasing in the ex ante incentive intensity since greater incentives result in higher performance and hence a higher probability of exceeding the fixed benchmark. Therefore, empirical validation of Proposition 4 will not only lend support to our model's general predictions, but also to the specific assumption that the supervisor is concerned about bonus equality with respect to an endogenously determined bonus benchmark.

We now consider the degree of renegotiation, $Y$, defined as the absolute value of $\Delta \alpha$. By Equation 12 , when $\Delta \alpha \geq 0$,

$$
Y=\Delta \alpha=\frac{0.5 Z-\theta-\frac{1}{\alpha^{*} \lambda}}{\frac{0.5}{\gamma}+\frac{1}{Z \lambda \gamma \alpha^{*}}+\frac{\theta}{\alpha^{*}}}
$$

Clearly, the above expression is increasing in $\alpha^{*}$, thus the degree of renegotiation $Y$ is increasing in $r$ and $\beta$ for upward renegotiation. The comparative statics with respect to $Z$ and $\gamma$ are ambiguous, because the above expression is increasing in these two parameters for fixed $\alpha^{*}$, but $\alpha^{*}$ is increasing in them. For downward renegotiation, by Equation 11, we have

$$
Y=-\Delta \alpha=\frac{-0.5 Z+\theta+\frac{1}{\alpha^{*} \lambda}}{\frac{0.5}{\gamma}+\frac{1}{Z \lambda \gamma \alpha^{*}}+\frac{\theta}{\alpha^{*}}} \frac{\lambda \beta^{2}}{1+\lambda \beta^{2}}
$$

For large $\lambda$, the above expression is increasing in $\alpha^{*}$ because the denominator is decreasing in $\alpha^{*}$, and the numerator is not much affected by $\alpha^{*}$. Thus, the degree of renegotiation $Y$ is also increasing in $r$ and $\beta$ for downward renegotiation. As above, the comparative statics with respect to $\gamma$ and $Z$ are ambiguous. Summarizing, we have

Proposition 5 The degree of renegotiation, namely, the absolute value of the difference between ex post and ex ante incentive intensities, $Y=|\Delta \alpha|$, is increasing in $r$ and $\beta$.

Proposition 5 states that the degree of renegotiation will be greater when the supervisor faces stronger incentives herself (larger $r$ ), or when the manager has greater career concerns (larger $\beta$ ). The reason for these results is as follows. For larger $r$ or larger $\beta$, the optimal ex ante incentive intensity $\alpha^{*}$ and the managerial effort $e^{*}$ will be greater. As a result, the bonus benchmark will be higher. If a manager's performance falls below this benchmark, his bonus payment will be adjusted upwards to the benchmark during the ex post renegotiation stage. In this case of upward renegotiation, the higher the benchmark, the greater the degree of renegotiation. If a manager's performance exceeds the bonus benchmark, his bonus payment will be reduced to a 
linear combination of the ex ante bonus payment and the bonus benchmark during the ex post renegotiation stage. In this case of downward renegotiation, the degree of renegotiation, namely the amount of adjustment, will be greater if the ex ante bonus payment and the benchmark both are larger.

¿From Proposition 5, for both downward and upward renegotiations, we obtain the same comparative statics results about the amount of bonus adjustment. These predictions cannot be easily anticipated if one is considering a model with renegotiation using an exogenously fixed bonus benchmark. Empirical validation of these predictions will lend strong support to our model.

\section{Data}

The data were collected by one of the authors and colleagues from rural China during the summer of 1998. The survey randomly sampled 59 townships in 15 counties in Jiangsu and Zhejiang, two of China's most developed coastal provinces, one north and the other south of Shanghai. As discussed earlier, the hierarchical structure of China's banking system resembles and parallels the government's administrative system; thus, each township surveyed has one ABC branch and one RCC branch. In only three instances was a bank branch missing from the survey, and in total, $57 \mathrm{ABC}$ and $58 \mathrm{RCC}$ branches were sampled.

The bank survey had two main components. The first component, conducted through interviews with township branch managers, acquired detailed information about branch managers' incentive contracts, actual execution of the contracts, and information about manager characteristics such as age, education, and years of residence in the township. Accountants of the bank branches provided the second part of the data by filling out a set of financial tables from their branch's financial accounting records. For various reasons outside our control, there are a certain number of observations with missing values on performance and contract data. ${ }^{18}$ Since our study requires information on performance and contractual terms, we end up with 59 valid observations

\footnotetext{
${ }^{18}$ One reason some branches' accounting books were not available was the absence of the accountants at the time of survey. There were also failures to report typical happenings to some surveyees. In a number of cases no ex ante contracts were reported, which indicates that relational contracts (i.e., informal agreements honored by reputations of both parties) were probably playing important roles. Due to our focus on contract renegotiations, observations with missing contract terms such as these had to be dropped, since in such cases contract renegotiations were not observable to us. We believe that most of the missing values are unlikely to cause serious sample selection biases.
} 
on incentive contracts and 60 on bank performance. Despite the small sample size, this dataset is still quite valuable, given the rich information about contracts and renegotiations it contains.

For both $\mathrm{ABC}$ and $\mathrm{RCC}$ branches in our dataset, a typical incentive contract for branch managers is constructed as follows. First, the contract specifies a number of performance measures: deposit growth, loan performance (i.e., percentage of performing loans), bank safety, and other administrative and party duties. Each performance measure is scaled to points, where typically 100 points correspond to the performance target the supervisor at the county bank sets for the branch manager. To get a measure of overall performance, the contract uses a weighting system, assigning relative weight to each performance measure. For example, if deposit growth, loan performance and all other measures have weights of $25 \%, 25 \%$ and $50 \%$, and a branch manager receives 90,80 , and 100 points on the three measures, then his overall performance amounts to 92.5 points. Finally, the contract specifies the amount of bonus each performance point is worth. In the previous example, if each performance point is worth 50 yuan, then the branch manager should get 4,625 yuan, according to the contract. Supervisors at county banks determine the weighting system and the incentive intensity (i.e., how much each performance point is worth) for each branch manager under her supervision.

In our empirical study, we will focus on deposit growth and loan performance and ignore other performance measures. Deposit growth and loan performance are the key measures of economic performance of bank branches, and are the most important among all performance measures in the weighting system, with an average weight of 25 and 26 percent respectively (Table 1 ). In some cases, the weight is as high as 75 percent for deposit growth, and in others, loan performance accounts for an even greater weight. Other measures, accounting for less than $50 \%$ on average in the weighting system, are mainly non-business oriented (e.g., bank safety, administrative and party duties) and hard for outside observers to interpret. Profit does enter into the contracts of some branch managers, but its weight is generally low (less than 10 percent on average), and nearly half of the branches have zero weight for profit. It is understandable that profit plays little role in this case, because it is hard to measure, and bank branches have little control over many of the variables (e.g., interest rates, wages, and numbers employed) that affect profits.

Focusing on deposit growth and loan performance, we construct a weighted branch performance measure that equals the weighted average of deposit growth and percentage of performing loans, where the weights are their respective incentive weights. This will be used as the empir- 
ical measure of the overall branch performance $x$ in our theoretical model. ${ }^{19}$ Table 1 reports the summary statistics of the performance measures and other variables. In our sample, bank deposits on average grew 21 percent, the same as deposit growth rates in both Jiangsu and Zhejiang provinces in the same year (1997). Percentage of performing loans was on average 85 percent of all the loans in the sample branches, somewhat higher than the national average. ${ }^{20}$ Both performance measures, as well as the weights, exhibit a great deal of variation across bank branches in the sample. The weighted branch performance measure we construct has a mean of 0.28 and a standard deviation of 0.17 , with a minimum of 0.02 and a maximum of 1.16.

Information on contract terms is also reported in Table 1. On average, branch managers in our sample get paid a fixed wage of 9,480 yuan, and a year-end bonus of 3,980 yuan, about 42 percent of the fixed wage. This indicates that incentive schemes are important for branch managers since bonuses are a quite significant portion of their total income. It can also be seen that both the fixed wage and the bonus have quite large variations in the sample.

In the ex ante contracts, the bonus reward for each performance point has a mean of 47.61 yuan and a standard deviation of 34.56, with a minimum of only 4.5 yuan and a maximum of a hefty 216. Since we focus on deposit growth and loan performance, we define the ex ante incentive intensity corresponding to $\alpha$ in the model as the bonus reward per performance point specified in the ex ante contracts weighted by deposit growth and loan performance. Specifically, the ex ante incentive intensity $\alpha$ is defined as the total weights on deposit growth and loan performance multiplied by the bonus reward per performance point and then divided by the fixed wage (in thousand yuan). We use the fixed wage as a normalization, because fixed wage variations largely reflect the differences in standard of living across locations. Our empirical results are qualitatively unchanged if we drop this normalization. As can be seen from Table 1, before normalization, the ex ante incentive intensity has a mean of 24.33 yuan per weighted performance point and a

\footnotetext{
${ }^{19}$ Here we do not consider issues of effort allocations related to multi-tasks (Holmstrom and Milgrom, 1991). Multitasking is an important topic that deserves thorough investigation, but this is beyond the scope of this paper. Moreover, it appears that the relative weights of different performance measures were very close within each county, and thus probably reflected county supervisors' preferences. For our purpose, it is acceptable to use the composite measure of performance for the following two reasons. First, contract renegotiations were about incentive intensities (i.e., bonus payment per performance point) but not the weighting system. Second, we get similar regression results by using deposit growth and loan performance separately as managers' performance measures.

${ }^{20}$ It is commonly believed that performing loans account for less than $80 \%$ of all loans nationwide (see, e.g., World Bank, 1997; Wei, 2000).
} 
standard deviation of 22.71. After normalization, it has a mean of 2.72 and a standard deviation of 2.22 .

Of course, managers did not get paid the bonus rewards exactly as specified in the ex ante contracts. Contract renegotiations took the form of adjusting the reward per performance point. From Table 1, the ex post reward per point has a mean of 41.35 yuan, a markdown from the ex ante reward per point of 47.61 yuan. As with the ex ante incentive intensity, we define the ex post incentive intensity corresponding to $\alpha^{\prime}$ in the model as the bonus reward per performance point actually paid to the managers weighted by deposit growth and loan performance. The ex post incentive intensity has a mean of 21.40 yuan per weighted performance point and a standard deviation of 22.71. After being normalized by the fixed wage, it has a mean of 2.42 and a standard deviation of 2.01 .

Renegotiations of incentive contracts were prevalent in our dataset. On the whole, 93 percent of incentive contracts were ex post renegotiated to varying degrees, of which 27 percent were renegotiated upward, and 66 percent renegotiated downward. The difference between ex post and ex ante incentive intensity, corresponding to $Y$ in the model, amounts to 4.95 yuan per point on average, which is about 23 percent of the ex ante incentive intensity.

Table 1 also reports the summary statistics of other variables used in the empirical analysis. We use the ratio of bonus to fixed wage of county bank employees, termed "the county bank's performance incentive," to measure the supervisor's incentive intensity, $r$, in the model. This ratio is on average 0.77 , significantly higher than that of township branch managers. Following Chavilier and Ellison (1999) and others in the existing literature on managerial career concerns, we use age to proxy branch managers' career concerns. The idea is simply that the younger the manager, the greater the importance of future career advance. Conversely, the greater a manager's age is, the smaller is the $\beta$ he has in our model. We use education and years of residence in the township to measure the branch manager's human capital, on the assumption that managers with more education and living in the locality longer (i.e., with more local experience) have a lower effort cost (smaller $\gamma$ in the model). Finally, the riskiness of the environment, $Z$ in the model, is proxied by the range of the annual growth rates of per capita real industrial GDP in the townships during the period 1994-1997. ${ }^{21}$

\footnotetext{
${ }^{21}$ For example, if the annual growth rates of per capita real industrial GDP in a township were $10 \%, 20 \%$ and $40 \%$ during 1994-1997, then $Z=0.3$. In some townships this range was quite dramatic (the largest was over $200 \%$ ), because the Township-Village Enterprise sector in Zhejiang and Jiangsu provinces experienced drastic ups and downs during 1994-1997.
} 


\section{Empirical Tests}

In this section we present results testing the theoretical predictions of the model regarding the $e x$ ante incentive intensity (Proposition 2), branch performance (Proposition 3) and renegotiations (Propositions 4 and 5). Since these propositions are comparative statics results, we can employ ordinary least squares (OLS) regressions for these tests.

\subsection{The $E x$ Ante Incentive Intensity}

Proposition 2 states that the ex ante incentive intensity $(\alpha)$ increases with the county supervisor's performance incentives $(r)$, the township manager's career concerns $(\beta)$, and the township manager's human capital $(-\gamma)$, but decreases with the riskiness of the environment in the township $(Z)$. The linear regression for testing Proposition 2 can be expressed as the following:

$$
\alpha=a_{0}+a_{1} * r+a_{2} * \text { age }+a_{3} * \text { education }+a_{4} * \text { year } s+a_{5} * Z+\epsilon
$$

where age proxies for smaller career concerns, education and years of residence in the township proxy for human capital, $a_{0}$ to $a_{5}$ are coefficients, and $\epsilon$ is the residual. To control for any potential difference between $\mathrm{ABC}$ and $\mathrm{RCCs}$, we also include a bank type indicator $(\mathrm{ABC}=1$, $\mathrm{RCCs}=0)$ in some specifications. Proposition 2 predicts that $a_{1}>0, a_{2}<0, a_{3}>0, a_{4}>0$ and $a_{5}<0$.

Regression results support the main predictions of Proposition 2. In Table 2, we report five different specifications of the test, with different combinations of the independent variables. For comparison, the signs predicted by the theory are reported in the first column. The major findings are the following. First, consistent with the theoretical prediction, the county bank's performance incentives have a positive effect on the township manager's ex ante incentive intensity. It is significant at the five percent level for two cases and at the 10 percent level for one case. The estimate of the coefficient is between 1.529 and 2.265, which means that an increase in the county bank performance incentive (bonus wage ratio) by one standard deviation (0.36) will increase the township branch's ex ante incentive intensity by between 20 and 30 percent of its mean. ${ }^{22}$

Second, the branch manager's age has a negative effect on his ex ante incentive intensity, which supports the hypothesis that the branch manager's career concerns have a positive effect

\footnotetext{
${ }^{22}$ These percentages are calculated by $1.529 * 0.36 / 2.72$ and $2.256 * 0.36 / 2.72$, where 2.72 is the mean of the township branch's ex ante incentive intensity.
} 
on the ex ante incentive intensity. It is significant at the 10 percent level in two cases. If we use the estimated coefficients in column (5) as an example, then a five-year younger manager will have a 17 percent larger ex ante incentive intensity. As younger managers are more concerned about career prospects, this regression result lends support to our theoretical prediction that the ex ante incentive intensity increases with career concerns.

Third, managers with more education and local experience end up ex ante with contracts with greater incentive intensity. The two human capital proxies, education and years of residence in the township, have the expected signs, although only the coefficient of education is significant at the 10 percent level in two cases.

Finally, the estimated effect of the range of township industrial growth does not have the expected sign. In a sense, this is consistent with other findings in the literature, summarized in Table 1 of Prendergast (2002b), that incentives and risk are positively correlated. Prendergast (2000, 2002a, b) provides several theoretical explanations for why, contrary to the prediction of the standard moral hazard model, incentives can be positively correlated with risk. These explanations include (i) supervisor favoritism; (ii) costly investigations; and (iii) firms' trade-off between direct monitoring and delegation. These effects may operate in our settings to cause the positive correlation between incentives and risk (proxied by the range of township industrial growth).

\subsection{Bank Performance}

Proposition 3 states that bank performance increases with the county supervisor's performance incentives, the township manager's career concerns, and the township manager's human capital, but decreases with the riskiness of the environment in the township. We test Proposition 3 by using the weighted performance measure as the dependent variable with the following regression specification:

$$
x=a_{0}+a_{1} * r+a_{2} * \text { age }+a_{3} * \text { education }+a_{4} * \text { years }+a_{5} * Z+\epsilon
$$

Proposition 3 predicts that $a_{1}>0, a_{2}<0, a_{3}>0, a_{4}>0$ and $a_{5}<0$.

Table 3 reports the regression results. They are mostly consistent with the predictions of Proposition 3. The county supervisor's performance incentives have the expected positive sign, and are significant at the five percent level in all specifications. The age of the manager has a negative and significant effect on bank performance, and this effect is robust to all specifications. 
This means that younger managers, who have greater career concerns, perform better than their older peers, holding other things equal. The two human capital variables, education and years of residence in the township, have the expected signs, but the effects are relatively weak. Only the manager's education is significant in one case. Finally, the range of industrial growth again does not have the expected sign and is not significant.

\subsection{Renegotiations}

Proposition 4 predicts that the likelihood of upward renegotiation is increasing with the county supervisor's performance incentives, the branch manager's career concerns, and the branch manager's human capital. To test Proposition 4, we use an indicator variable that equals one if the contract was renegotiated upward and zero otherwise, and employ a probit model to estimate the probability of upward renegotiation. The independent variables are the same as before.

The results of the probit model in general support the predictions of Proposition 4. Table 4 reports the marginal effects of the independent variables on the probability of upward renegotiation. The county supervisor's performance incentives have a positive and statistically significant effect on the probability of upward renegotiation as predicted by our model. This effect is also economically substantial. When the county supervisor's incentive intensity (bonus wage ratio) increases by one standard deviation (0.36), the probability of an upward renegotiation will go up by 13-17 percent. Equally important, the probit model also shows that branch managers' career concerns have a positive effect on upward renegotiation. Manager's age has the expected negative sign and is significant at the 10 percent level in two cases. This means that younger managers are more likely to have their bonus rewards renegotiated upward. For example, if a branch manager is 5 years younger than the mean, the chance for an upward renegotiation will be 6-10 percent higher. Finally, the two human capital measures, education and years of residence, have the expected positive signs but are not statistically significant.

Proposition 5 predicts that the degree of renegotiation increases with the county supervisor's incentive intensity and the branch manager's career concerns. Employing OLS regressions, we test Proposition 5 using the difference between ex ante and ex post incentive intensities (normalized by fixed wage) as the dependent variable and the same set of independent variables as before. Regression results are reported in Table 5. They support Proposition 5. The county supervisor's incentive intensity has a positive effect on the degree of renegotiation, and it is significant at the 10 percent level in all cases. None of the other variables has a significant effect on the degree of 
renegotiation.

To summarize, the empirical test results in general support the theoretical predictions of our model. Due to the limitations of the data, not all variables have statistically significant effects as the model predicts. However, in most of the cases, the key variables have both statistically and economically significant effects just as the model predicts. In particular, the regression results support our predictions about the direction and degree of renegotiation, which do not follow from simple intuitive arguments. Overall, the empirical evidence indicates that contract renegotiations in the Chinese banking industry are at least partially driven by the trade-off between supervisors' equality concerns and managers' career concerns. Incentive contracts do affect performance, but they do so through mechanisms more complicated than the standard agency model suggests. Institutional environment and organizational features shape the ways incentive contracts operate to affect performance.

\section{Conclusions}

Motivated by the observations coming from the Chinese banking industry, we build a model of incentive contracting and renegotiation that incorporates some of the essential organizational features of the Chinese state banks into the standard agency framework. In our model, incentive contracts are almost always renegotiated in equilibrium, yet they still affect performances even though renegotiation is fully anticipated. Contract renegotiations result from the tradeoff between supervisors' equality concerns over income distribution of their subordinates, and managers' career concerns which come largely under their supervisors' discretion. Our model generates a rich set of implications regarding optimal contract design, performance, and the direction and degree of renegotiations. We then use a dataset from the Chinese banking industry to test these predictions. Overall, our theory of renegotiation fits the evidence quite well.

Although our theory of renegotiation is motivated by and tested with observations of the Chinese state banks, we believe it has wider implications. What drive our results are supervisors' equality concerns and managers' career concerns which come under the control of their supervisors. These elements seem to be present in the contractual relationships within the hierarchical structures of many organizations. We therefore believe that our theory can extend to a wide variety of contexts in China and elsewhere.

One natural extension can be seen in the contract renegotiations which are conducted as part of the fiscal relations between Chinese central and local governments. In particular, consider the 
so-called "fiscal contracting system" adopted in the period, 1980-1993 (Shirk, 1993). Researchers have long noticed the high and pervasive levels of complaints among provincial officials about the central government's discretions in the enforcement of intergovernmental fiscal contracts. For instance, the central government "created" numerous means to level up revenue-submission ratios for those provinces exhibiting good fiscal performance, including "forced borrowing" or reclaiming central ownership of lucrative local firms (Wong et al., 1995; Ma, 1997). However, there is also evidence that, despite these enforcement problems, provincial officials still responded to fiscal contract incentives (Jin et al., 2000). In light of our theory, a plausible explanation is that the presence of strong career concerns of provincial officials allowed the equality-concerned central government to renegotiate fiscal contracts while not destroying the incentives completely. Our model also suggests that it may be an over-simplification to draw conclusions about the effects of the incentive system on provincial fiscal performance simply by regressing performance on incentive intensity of the agreements.

With certain modifications, our theory has the potential to shed light on incentive contracting and renegotiations in organizations outside China. Obviously there are large differences in organizational structures between a typical Chinese state bank and, say, Citibank. Citibank itself may not emphasize income equality among its managers and may not impose it on the supervisors as the Chinese bank does. Unlike their counterparts in the Chinese banks, Citibank managers' careers are not completely tied with the bank, and they certainly care about their outside market values. Despite these differences, the two critical assumptions of our model, supervisors' equality concerns and managers' career concerns and rent-on-the-job at the supervisors' discretion, are still valid for firms in the developed economies. Supervisors in large corporations in the developed economies may still care about income equality of their subordinates, either on account of fairness considerations or because of their concerns about costly influence activities. Moreover, the managerial market may not be perfectly competitive due to information problems, so managers may still have rents on the job that are at least partially controlled by their supervisors. For example, the outside market may not observe individual managers' performances except via promotion by their supervisors, which gives a substantial degree of discretion to the supervisors over managers' market values.

Most directly, our model can provide useful insights on contract renegotiations within firms in the developed economies. While no systematic evidence is available on contract renegotiations in developed economies, anecdotal evidence can be found scattered in the existing literature, 
especially in works on relational contracting (see, e.g., Levin, 2003). ${ }^{23}$ In the literature on relational contracting, firms use discreational, non-binding bonus promises to motivate managers to exert efforts, while the bonus promises are made credible through repeated interactions (relational capital). It is natural to consider situations in which firms or supervisors use bonuses and future promotions to motivate managers. In a multi-agent setting, these incentive instruments may preesnt interesting interactions when supervisors have equality concerns and managers have career concerns. ${ }^{24}$ For future research, it would be interesting to extend our model to incorporate relational contracting and outside managerial markets.

Our model may also shed light on why supervisors tend to have centrality and leniency biases and what effects these biases have on incentives. In our model, if the supervisor does not control the incentive scheme for her managers but is required to report their performances, then, motivated by the equality concerns, she will indeed exhibit centrality and leniency biases in her reports. In that case, renegotiations of incentive contracts will not take the form of adjusting incentive intensity as in the current model. Rather, due to her equality concerns, the supervisor will distort her reports about the managers' performances upwards for poor performances and downward for good performances, leading to the centrality bias. One implication of our model would suggest that a substantial amount of incentives can still be preserved in this system if the supervisor has discretion over managers' career concerns and rent-on-the-job. Related to this, our model may suggest one rationale for the wide use of firm-level performance pay schemes, namely, to reduce ex post renegotiations which trade off supervisors' equality concerns and managers' career concerns. Such trade-offs could be more costly to firms than what the current model allows, if it is important for firms to promote the "right" types of managers. The model in this paper is very simple and highly stylized. It can certainly be extended in future research to incorporate other organizational features of firms to explain other interesting phenomena like the examples given here.

\footnotetext{
${ }^{23}$ Levin (2003) cited several cases in which managers did not get the bonuses promised to them and quit the firms. Such cases represent failed attempts to renegotiate bonuses, which suggests that renegotiations of bonuses take place in firms quite commonly.

${ }^{24}$ See Rayo (2003) for a model with multiple agents and mutliple incentive instruments.
} 


\section{Appendix}

Proof of Proposition 1: Recall that S's expected payoff can be written as

$$
E v=A+\int_{0}^{\bar{\theta}} v_{1} / Z d \theta+\int_{\bar{\theta}}^{Z} v_{2} / Z d \theta
$$

where $\bar{\theta}=0.5 Z-1 /(\alpha \lambda)$, and $v_{1}$ and $v_{2}$ are given by Equations 5 and 3 , respectively.

Rewriting Equation 5 gives

$$
v_{1}=r e^{*}+r \theta-\alpha\left(e^{*}+0.5 Z\right)+0.5 / \lambda=(r-\alpha) e^{*}-0.5 Z \alpha+r \theta+0.5 / \lambda
$$

Since $\alpha x-\bar{b}=\alpha\left(e^{*}+\theta\right)-\alpha\left(e^{*}+0.5 Z\right)=\alpha(\theta-0.5 Z)$, by Equation 3, we have

$$
v_{2}=v_{1}-\frac{0.5 \lambda(\alpha x-B)^{2}}{1+\lambda \beta^{2}}=v_{1}-\frac{0.5 \lambda[\alpha(\theta-0.5 Z)+1 / \lambda]^{2}}{1+\lambda \beta^{2}}
$$

Plugging in the values of $v_{1}$ and $v_{2}$ into $E v$ gives

$$
\begin{aligned}
E v & =A+(r-\alpha) e^{*}-0.5 Z \alpha+0.5 r Z+0.5 / \lambda-\frac{0.5 \lambda}{Z\left(1+\lambda \beta^{2}\right)} \int_{\bar{\theta}}^{Z}[\alpha(\theta-0.5 Z)+1 / \lambda]^{2} d \theta \\
& =A+0.5(r Z+1 / \lambda)+(r-\alpha) e^{*}-0.5 Z \alpha-\frac{\lambda}{6 \alpha Z\left(1+\lambda \beta^{2}\right)}(0.5 Z \alpha+1 / \lambda)^{3} \\
& =C+(r-\alpha) e^{*}-0.5 Z \alpha-\frac{\lambda}{6 Z\left(1+\lambda \beta^{2}\right)}\left[(0.5 Z)^{3} \alpha^{2}+3(0.5 Z)^{2} \alpha / \lambda+1 /\left(\alpha \lambda^{3}\right)\right]
\end{aligned}
$$

where $C$ is a constant.

The FOC with respect to $\alpha$ is

$$
\begin{aligned}
& (r-\alpha) \frac{d e^{*}}{d \alpha}-e^{*}-0.5 Z-\frac{\lambda}{6 Z\left(1+\lambda \beta^{2}\right)}\left[2(0.5 Z)^{3} \alpha+3(0.5 Z)^{2} / \lambda-1 /\left(\alpha^{2} \lambda^{3}\right)\right] \\
= & \frac{0.5 r-\alpha}{\gamma}-\frac{1}{Z \gamma \lambda}-0.5 Z-\frac{1}{6 Z\left(1+\lambda \beta^{2}\right)}\left[\lambda Z^{3} \alpha / 4+3 Z^{2} / 4-1 /(\alpha \lambda)^{2}\right] \\
= & 0
\end{aligned}
$$

Simplifying it, we have

$$
\frac{3 r Z\left(1+\lambda \beta^{2}\right)}{\gamma}-\frac{6\left(1+\lambda \beta^{2}\right)}{\gamma \lambda}-3 Z^{2}\left(\lambda \beta^{2}+1.25\right)+\frac{1}{(\alpha \lambda)^{2}}=\alpha\left[\lambda Z^{3} / 4+\frac{6 Z\left(1+\lambda \beta^{2}\right)}{\gamma}\right]
$$

It is easy to check that S's objective function is globally concave in $\alpha$, thus the first order condition gives the optimal effort choice. 
The exact solution to this equation is not easy to obtain. However, the solution is easy to visualize. The right hand side is linear in $\alpha$, and can be thought of as the marginal cost of $\alpha$. The left hand side can be thought of as the marginal benefit of $\alpha$. It consists of several constant terms plus $1 /(\alpha \lambda)^{2}$, hence is strictly decreasing in $\alpha$. From the shapes of the marginal cost and benefit of $\alpha$, clearly there is a unique solution to the first order condition. As an approximation, we suppose that $\lambda^{2}$ is sufficiently large relative to the other parameters in the model and relative to the feasible range of $\alpha$, so that the term $1 /(\alpha \lambda)^{2}$ on the left hand side is sufficiently small and thus can be omitted. This approximation makes the marginal benefit curve flat and shifts it down, resulting in underestimation of $\alpha$. However, the properties of the solution, in particular the comparative statics with regard to other parameters, are not affected by this approximation. That $\mathrm{S}$ cares strongly about wage equality (large $\lambda$ ) is also a reasonable assumption in the institutional environment of the Chinese state banks.

With this approximation, we can solve for $\alpha$ from the first order condition:

$$
\alpha^{*} \cong \frac{3 r Z-\frac{6}{\lambda}-3 \gamma Z^{2}\left(1+\frac{1}{4\left(1+\lambda \beta^{2}\right)}\right)}{\frac{\lambda \gamma Z^{3}}{4\left(1+\lambda \beta^{2}\right)}+6 Z}
$$

By Equations 9 and 10, we get M's effort choice as

$$
e^{*}=0.5 \alpha^{*} / \gamma+1 /(Z \gamma \lambda) \cong \frac{3 r Z-\frac{6}{\lambda}-3 \gamma Z^{2}\left(1+\frac{1}{4\left(1+\lambda \beta^{2}\right)}\right)}{\frac{\lambda \gamma^{2} Z^{3}}{2\left(1+\lambda \beta^{2}\right)}+12 \gamma Z}+\frac{1}{Z \lambda \gamma}
$$

M's performance is simply $x=e^{*}+\theta$.

By Equations 2, 4 and 10, we obtain the ex post incentive intensity as follows. When $\theta \geq \bar{\theta}$, or $\alpha^{*} x \geq B$, the ex post incentive intensity is given by

$$
\begin{aligned}
\alpha^{\prime} & =\alpha^{*} \frac{1}{1+\lambda \beta^{2}}+\frac{\alpha^{*}\left(e^{*}+\theta\right)+\alpha^{*}(0.5 Z-\theta)-1 / \lambda}{x} \frac{\lambda \beta^{2}}{1+\lambda \beta^{2}} \\
& \left.=\alpha^{*}\left[1-\frac{\theta-0.5 Z+1 /\left(\alpha^{*} \lambda\right.}{x}\right) \frac{\lambda \beta^{2}}{1+\lambda \beta^{2}}\right]
\end{aligned}
$$

When $\theta<\bar{\theta}$, or $\alpha^{*} x<B$, the ex post incentive intensity is given by

$$
\alpha^{\prime}=\alpha^{*}\left[1+\frac{0.5 Z-1 /\left(\alpha^{*} \lambda\right)-\theta}{x}\right]
$$

So the proposition is proven. 


\section{References}

[1] Chevalier, J., and G. Ellison. 1999. "Career Concerns of Mutual Fund Managers." Quarterly Journal of Economics 114: 389-432.

[2] Coens, T. and M. Jenkins. 2000. Abolishing Performance Appraisals: Why They Backfire and What to Do Instead. San Francisco: Berrett-Koehler Publishers.

[3] Dewatripont, M. 1989. "Commitment Through Renegotiation-Proof Contracts with Third Parties." The Review of Economic Studies, Vol. 55, No. 3. (Jul., 1988), pp. 377-389.

[4] Dewatripont, M. 1989. "Renegotiation and Information Revelation over Time: The Case of Optimal Labor Contracts." Quarterly Journal of Economics, 104: 589-619.

[5] Dipchand, C., Y. Zhang, and M. Ma. 1994. The Chinese Financial System. Connecticut: Greenwood Press.

[6] Fehr, E., and K. Schmidt. 2003, "Theories of Fairness and Reciprocity - Evidence and Economic Applications," in Advances in Economics and Econometrics: Eighth World Congress of Econometric Society Monographs, eds. Dewatripont, M., L. Hansen, and S. Turnovsky, vol 1:208-257. Cambridge, Cambridge University Press.

[7] Fudenberg, D., and J. Tirole. 1990. "Moral Hazard and Renegotiation in Agency Contracts." Econometrica58: 1279-1320.

[8] Gibbons, R., and K. Murphy. 1992. "Optimal Incentive Contracts in the Presence of Career Concerns: Theory and Evidence." Journal of Political Economy 100:468-505.

[9] Gibbons, R., and M. Waldman. 1999, "Careers in Organizations: Theory and Evidence." in O. Ashenfelter and D. Card, eds., Handbook of Labor Economics, 3B, Chapter 36.

[10] Groves, T., Y. Hong, J. McMillan, and B. Naughton. 1994. "Autonomy and Incentives in Chinese State Enterprises." Quarterly Journal of Economics 103(4): 183-209.

[11] Holmstrom, B. 1999. "Managerial Incentive Problems: A Dynamic Perspective." Review of Economic Studies, LXLI, pp169-182.

[12] Holmstrom, B., and P. Milgrom, 1991, "Mutlitask Principal-Agent Analyses: Incentive Contracts, Asset Ownership, and Job Design." Journal of Law, Economics, and Organization $57: 25-52$. 
[13] Jefferson, D., and H. Rawski. 1999. Ownership, Performance and Economic Reforms. Oxford: Oxford University Press.

[14] Jin, H., Y. Qian, and B. Weingast. 2000. "Regional Decentralization and Fiscal Incentives: Federalism, Chinese Style." mimeo.

[15] Kornai, J. 1980. Economics of Shortage. Amsterdam: North-Holland.

[16] Kornai, J. 1992. The Socialist System: The Political Economy of Communism. Oxford, UK: Oxford University Press.

[17] Laffont, J., and J. Tirole. 1988. "The Dynamics of Incentive Contracts." Econometrica, Vol. 56, No. 5., pp. 1153-1175.

[18] Levin, J. 2003. "Relational Incentive Contracts." American Economic Review, vo1.93 no.3, pp. $835-857$.

[19] Li, W. 1997. "The Impact of Economic Reform on the Performance of Chinese State Enterprises, 1980-1989". Journal of Political Economy 105: 1080-1106.

[20] Ma, J. 1997. Intergovernmental Relations and Economic Management in China. New York: St. Martin's Press.

[21] Milgrom, P. 1988. "Employment Contracts, Influence Activities, and Efficient Organization Design." Journal of Political Economy, Vol. 96, No. 1. pp. 42-60.

[22] Murphy, K. R. and J. Cleveland. 1991. Performance Appraisal: An Organizational Perspective. Boston: Allyn and Bacon.

[23] Naughton, B. 1995. Growing out of the Plan. Cambridge: Cambridge University Press.

[24] Park, A., L. Brandt, and A. Giles. 1997. "Giving Credit Where Credit is Due: The Changing Role of Rural Financial Institutions in China." mimeo.

[25] Prendergast, C. 1999. "The Provision of Incentives in Firms," Journal of Economic Literature, $37,7-63$.

[26] Prendergast, C. 2002. "What Trade-Off of Risk and Incentives?" Amercian Economic Review, 90:421-425. 
[27] Prendergast, C. 2002a. "Uncertainty and Incentives," Journal of Labor Economics, 20:s115s137.

[28] Prendergast, C. 2002b. "The Tenuous Trade-off Between Risk and Incentives," Journal of Political Economy, 110:1071-1102.

[29] Rayo, L. 2003. "Relational Team Incentives and Ownership," forthcoming, American Economic Review.

[30] Shirk, S. 1993. The Political Logic of Economic Reform in China. University of California Press.

[31] Wei, F. 2000. China's Financial Sector Reform in the Transition to a Market Economy: Key Issues and Policy Options. Hamburg: LIT.

[32] Wong, C., C. Heady, and W. Woo. 1995. Fiscal Management and Economic Reform in the People's Republic of China. Hong Kong: Oxford University Press.

[33] The World Bank. 1997. China 2020-Development Challenges in the New Reforms, A World Bank Country Study. Washington, D.C.: The World Bank. 
Table 1: Descriptive Statistics

Variables

Mean Standard Min Max

Deviation

Branch performance measures

Deposit growth (a)

Performing loans/all loans (b)

Weight on deposit growth (c) $(\%)$

Weight on loan performance (d) (\%)

Weighted bank performance measure $\left(a^{*} c+b * d\right)$

$\begin{array}{cccc}0.21 & 0.26 & -0.41 & 1.45 \\ 0.85 & 0.19 & 0.05 & 1.00 \\ 25.09 & 14.86 & 0 & 75 \\ 25.68 & 12.52 & 0 & 78.79 \\ 0.28 & 0.17 & 0.02 & 1.16\end{array}$

Wage and bonus reward schemes

Fixed wage (A) (1,000 yaun)

Ex ante reward per point (e) (yuan/point)

Ex post reward per point (f) (yuan/point)

9.48

47.6

2.73

3.48

18.00

Actual total bonus reward (1,000 yuan)

3.98

30.56

2.94

197.80

Branch incentive measures

Ex ante incentive intensity $(\mathrm{B}=\mathrm{c} * \mathrm{e}+\mathrm{d} * \mathrm{e})$

Normalized ex ante incentive intensity $(\mathrm{B} / \mathrm{A})$

Ex post incentive intensity $\left(\mathrm{C}=\mathrm{c} * \mathrm{f}+\mathrm{d}^{*} \mathrm{f}\right)$

0.2

18.0

Normalized ex post incentive intensity $(\mathrm{C} / \mathrm{A})$

24.33

2.72

22.71

2.22

21.40

19.87

1.3

118.8

2.42

2.01

0.38

9.90

Contract renegotiation measures

$\begin{array}{ll}\text { Proportion of contracts renegotiated } & 0.93\end{array}$

Upward renegotiation ( $1=$ upward renegotiation, $0=$ otherwise) $\quad 0.27$

Absolute amount of renegotiation $(|\mathrm{C}-\mathrm{B}|)$

4.95

Absolute amount of renegotiation normalized by wage $(|\mathrm{C}-\mathrm{B}| / \mathrm{A})$

0.57

7.40

0.87

0

35

$\begin{array}{llll}0.77 & 0.36 & 0.18 & 1.67\end{array}$

County bank's performance incentives (bonus/wage ratio)

Branch manager's age (years)

39.9

7.8

28

60

12.6

1.7

17.9

19.7

9

19

Branch manager's years of residence in the township

0.67

0.45

0

60

Range of industry growth rate during 1994-7

0.50

0.50

2.28 
Table 2: OLS Regressions Examining the Determinants of the ex ante Incentive Intensity

Dependent variable: ex ante incentive intensity (normalized)

Model

\section{Predicted}

$\begin{array}{llllll}\text { sign } & 1 & 2 & 3 & 4 & 5\end{array}$

County bank's performance incentives

(bonus/wage ratio, r)

$+2.265^{* *}$

1.529

$1.684^{*}$

$2.180^{* *}$

$(2.34)$

(1.57)

(1.78)

(2.27)

Bank manager's age (- $\beta)$

$\begin{array}{lll}- & -0.080^{*} & -0.084\end{array}$

$-0.070$

$-0.095^{*}$

$(-1.97)$

$(-1.66)$

$(-1.36)$

$(-1.77)$

Bank manager's education $(-\gamma)$

$+$

0.308

$0.367 * *$

0.288

0.263

(1.70) (2.04) (1.51)

(1.42)

Bank manager's years of residence in

$+$

0.023

0.005

0.024

0.023

the township $(-\gamma)$

(1.17)

(0.32)

(1.19)

(1.21)

Range of industry growth rate during 1994-7 (Z)

$0.978^{*}$

0.763

0.656

0.946

(1.71)

(1.29)

(1.13)

Bank type $(\mathrm{RCC}=0, \mathrm{ABC}=1)$

$-0.892$

$-0.780$

$-0.517$

$-0.821$

$(-1.52)$

$(-1.33)$

$(-0.92)$

$(-1.44)$

Constant

$4.032 * *$

0.660

$-3.304$

1.359

0.996

(2.52)

$(0.20)$

$(-1.28)$

$(0.41)$

(0.29)

R-Squared

0.13

0.12

0.12

0.11

0.17

Observations

59

59

59

59

59

a. Numbers in parentheses are t-ratios.

b. Significance level $0.1,0.05$ and 0.01 are noted by *, **, and ***. 
Dependent variable: weighted branchperformance

\begin{tabular}{|c|c|c|c|c|c|c|}
\hline Model & $\begin{array}{l}\text { Predicted } \\
\text { sign }\end{array}$ & 1 & 2 & 3 & 4 & 5 \\
\hline $\begin{array}{l}\text { County bank's performance incentives } \\
\text { (bonus/wage ratio, r) }\end{array}$ & + & $\begin{array}{c}0.115^{* *} \\
(2.18)\end{array}$ & $\begin{array}{c}0.126^{* *} \\
(2.24)\end{array}$ & $\begin{array}{c}0.096^{* *} \\
(2.04)\end{array}$ & & $\begin{array}{c}0.122^{* *} \\
(2.32)\end{array}$ \\
\hline Bank manager's age $(-\beta)$ & - & $\begin{array}{c}-0.007 * * \\
(-2.04)\end{array}$ & $\begin{array}{r}-0.007 * \\
(-1.84)\end{array}$ & & $\begin{array}{l}-0.006^{*} \\
(-1.70)\end{array}$ & $\begin{array}{r}-0.007^{*} \\
(-1.88)\end{array}$ \\
\hline Bank manager's education $(-\gamma)$ & + & & $\begin{array}{l}0.011 \\
(0.90)\end{array}$ & $\begin{array}{r}0.021^{*} \\
(1.80)\end{array}$ & $\begin{array}{l}0.010 \\
(0.81)\end{array}$ & $\begin{array}{l}0.009 \\
(0.69)\end{array}$ \\
\hline $\begin{array}{l}\text { Bank manager's years of residence in } \\
\text { the township }(-\gamma)\end{array}$ & + & & $\begin{array}{l}0.001 \\
(0.83)\end{array}$ & $\begin{array}{l}-0.001 \\
(-0.16)\end{array}$ & $\begin{array}{l}0.001 \\
(0.57)\end{array}$ & $\begin{array}{l}0.001 \\
(1.03)\end{array}$ \\
\hline Range of industry growth rate during 1994-7 (Z) & - & $\begin{array}{l}0.052 \\
(1.10)\end{array}$ & & $\begin{array}{l}0.060 \\
(1.16)\end{array}$ & $\begin{array}{l}0.047 \\
(0.95)\end{array}$ & $\begin{array}{l}0.052 \\
(1.11)\end{array}$ \\
\hline Bank type $(\mathrm{RCC}=0, \mathrm{ABC}=1)$ & & $\begin{array}{l}0.046 \\
(1.07)\end{array}$ & & $\begin{array}{l}0.036 \\
(0.85)\end{array}$ & $\begin{array}{l}0.056 \\
(1.17)\end{array}$ & $\begin{array}{l}0.047 \\
(1.05)\end{array}$ \\
\hline Constant & & $\begin{array}{l}0.418^{* * *} \\
(3.86)\end{array}$ & $\begin{array}{l}0.319 \\
(1.32)\end{array}$ & $\begin{array}{l}-0.107 \\
(0.62)\end{array}$ & $\begin{array}{l}0.332 \\
(1.43)\end{array}$ & $\begin{array}{l}0.299 \\
(1.22)\end{array}$ \\
\hline $\begin{array}{l}\text { R-Squared } \\
\text { Observations }\end{array}$ & & $\begin{array}{c}0.17 \\
60\end{array}$ & $\begin{array}{c}0.15 \\
60\end{array}$ & $\begin{array}{c}0.12 \\
60\end{array}$ & $\begin{array}{c}0.13 \\
60\end{array}$ & $\begin{array}{c}0.18 \\
60\end{array}$ \\
\hline
\end{tabular}

a. Numbers in parentheses are t-ratios.

b. Significance level 0.1, 0.05 and 0.01 are noted by $*, * *$, and ***. 
Table 4: Probit Regressions on the Determinants of Upward Contract Renegotiation

Dependent variable: 1 if upward renegotiation, 0 otherwise

\begin{tabular}{|c|c|c|c|c|c|c|}
\hline Model & $\begin{array}{l}\text { Predicted } \\
\text { sign }\end{array}$ & 1 & 2 & 3 & 4 & 5 \\
\hline $\begin{array}{l}\text { County bank incentive intensity } \\
\text { (bonus/wage ratio, r) }\end{array}$ & + & $\begin{array}{c}0.468^{* *} \\
(2.41)\end{array}$ & $\begin{array}{c}0.403^{* *} \\
(2.04)\end{array}$ & $\begin{array}{l}0.364^{*} \\
(1.84)\end{array}$ & & $\begin{array}{c}0.444^{* *} \\
(2.15)\end{array}$ \\
\hline Bank manager's age $(-\beta)$ & - & $\begin{array}{l}-0.012 \\
(-1.38)\end{array}$ & $\begin{array}{r}-0.018^{*} \\
(-1.75)\end{array}$ & & $\begin{array}{l}-0.016 \\
(-1.58)\end{array}$ & $\begin{array}{r}-0.019^{*} \\
(-1.85)\end{array}$ \\
\hline Bank manager's education $(-\gamma)$ & + & & $\begin{array}{l}0.021 \\
(0.45)\end{array}$ & $\begin{array}{l}0.036 \\
(0.75)\end{array}$ & $\begin{array}{l}0.017 \\
(0.35)\end{array}$ & $\begin{array}{l}0.013 \\
(0.29)\end{array}$ \\
\hline $\begin{array}{l}\text { Bank manager's years of residence in } \\
\text { the township }(-\gamma)\end{array}$ & + & & $\begin{array}{l}0.005 \\
(1.33)\end{array}$ & $\begin{array}{l}0.002 \\
(0.62)\end{array}$ & $\begin{array}{l}0.006 \\
(1.41)\end{array}$ & $\begin{array}{l}0.006 \\
(1.31)\end{array}$ \\
\hline Range of industry growth rate during $1994-7(\mathrm{Z})$ & & $\begin{array}{l}0.104 \\
(0.69)\end{array}$ & & $\begin{array}{l}0.102 \\
(0.62)\end{array}$ & $\begin{array}{l}0.087 \\
(0.55)\end{array}$ & $\begin{array}{l}0.134 \\
(0.82)\end{array}$ \\
\hline Bank type $(\mathrm{RCC}=0, \mathrm{ABC}=1)$ & & $\begin{array}{l}-0.036 \\
(-0.31)\end{array}$ & & $\begin{array}{l}-0.015 \\
(-0.13)\end{array}$ & $\begin{array}{l}0.055 \\
(0.45)\end{array}$ & $\begin{array}{l}-0.008 \\
(-0.07)\end{array}$ \\
\hline $\begin{array}{l}\text { R-Squared } \\
\text { Observations }\end{array}$ & & $\begin{array}{c}0.10 \\
60\end{array}$ & $\begin{array}{c}0.19 \\
60\end{array}$ & $\begin{array}{c}0.06 \\
60\end{array}$ & $\begin{array}{c}0.05 \\
60\end{array}$ & $\begin{array}{c}0.10 \\
60\end{array}$ \\
\hline
\end{tabular}

a. We report the marginal effects $(\mathrm{dF} / \mathrm{dx})$ rather than the coefficients. Numbers in parentheses are t-ratios.

b. Significance level $0.1,0.05$ and 0.01 are noted by $* * *$, and $* * *$. 
Table 5: OLS Regressions on the Determinants of the Degree of Contract Renegotiations

Dependent variable:

Degree of renegotiation (Absolute amount of renegotiation normalized by wage )

Model

Predicted

$\begin{array}{llllll}\text { sign } & 1 & 2 & 3 & 4 & 5\end{array}$

\begin{tabular}{|c|c|c|c|c|c|c|}
\hline $\begin{array}{l}\text { County bank incentive intensity } \\
\text { (bonus/wage ratio, r) }\end{array}$ & + & $\begin{array}{l}0.670^{*} \\
(1.84)\end{array}$ & $\begin{array}{l}0.674 * \\
(1.75)\end{array}$ & $\begin{array}{l}0.640^{*} \\
(1.82)\end{array}$ & & $\begin{array}{r}0.664 * \\
(1.79)\end{array}$ \\
\hline Bank manager's age $(-\beta)$ & - & $\begin{array}{l}-0.011 \\
(-0.76)\end{array}$ & $\begin{array}{l}-0.006 \\
(-0.30)\end{array}$ & & $\begin{array}{l}-0.003 \\
(0.14)\end{array}$ & $\begin{array}{l}-0.005 \\
(-0.21)\end{array}$ \\
\hline Bank manager's education $(-\gamma)$ & & & $\begin{array}{l}0.017 \\
(0.31)\end{array}$ & $\begin{array}{l}0.036 \\
(0.64)\end{array}$ & $\begin{array}{l}0.038 \\
(0.64)\end{array}$ & $\begin{array}{l}0.031 \\
(0.51)\end{array}$ \\
\hline $\begin{array}{l}\text { Bank manager's years of residence in } \\
\text { the township }(-\gamma)\end{array}$ & & & $\begin{array}{l}-0.001 \\
(-0.18)\end{array}$ & $\begin{array}{l}-0.003 \\
(-0.61)\end{array}$ & $\begin{array}{l}-0.002 \\
(-0.28)\end{array}$ & $\begin{array}{l}-0.002 \\
(-0.32)\end{array}$ \\
\hline Range of industry growth rate during 1994-7 (Z) & & $\begin{array}{l}-0.159 \\
(-0.75)\end{array}$ & & $\begin{array}{l}-0.209 \\
(-0.91)\end{array}$ & $\begin{array}{l}-0.288 \\
(-1.11)\end{array}$ & $\begin{array}{l}-0.200 \\
(-0.82)\end{array}$ \\
\hline Bank type $(\mathrm{RCC}=0, \mathrm{ABC}=1)$ & & $\begin{array}{l}-0.078 \\
(-0.32)\end{array}$ & & $\begin{array}{l}-0.093 \\
(-0.39)\end{array}$ & $\begin{array}{l}-0.002 \\
(-0.01)\end{array}$ & $\begin{array}{l}-0.095 \\
(-0.39)\end{array}$ \\
\hline Constant & & $\begin{array}{l}0.634 \\
(1.02)\end{array}$ & $\begin{array}{l}0.113 \\
(0.10)\end{array}$ & $\begin{array}{l}-0.122 \\
(-0.16)\end{array}$ & $\begin{array}{l}0.200 \\
(0.17)\end{array}$ & $\begin{array}{c}0.089 \\
(0.07)\end{array}$ \\
\hline $\begin{array}{l}\text { R-Squared } \\
\text { Observations }\end{array}$ & & $\begin{array}{c}0.05 \\
59\end{array}$ & $\begin{array}{c}0.05 \\
59\end{array}$ & $\begin{array}{c}0.06 \\
59\end{array}$ & $\begin{array}{c}0.02 \\
59\end{array}$ & $\begin{array}{c}0.06 \\
59\end{array}$ \\
\hline
\end{tabular}

a. Numbers in parentheses are t-ratios.

b. Significance level $0.1,0.05$ and 0.01 are noted by $*, * *$, and ***. 